\title{
Analysis on the Construction Framework and Realization Logic of Smart Laboratory System under the Environment of Internet of Things
}

\author{
Xin ying Wang* \\ Pingdingshan College, Henan 467002, China.
}

\begin{abstract}
The rapid growth of the Internet of Things has broken people's way of thinking and brought tremendous changes to people's lives. For key configurations, the Internet of Things is included in the central distribution component of cloud computing, transmission networks, and sensor acceptance techniques. The future Internet of Things is similar to the human body, with different induction and cognitive fields to complete functional tasks, and is a key component of work efficiency and the creation of intelligent control systems. The laboratory is a training ground for colleges and universities to cultivate creative and commercial talents, and has a special mission of cultivating skills and training talents. In recent years, the quality of laboratory knowledge has been greatly improved, but the management model can still meet the needs of teaching, laboratory and technology opening, scientific research, and the development of new and business talents. In the future, university laboratories should learn high-quality design ideas, use Internet of Things technology, Internet technology and ARM technology to build an effective intelligent management system to understand laboratory intelligence. Therefore, this article recommends a local Web-based laboratory construction program, aimed at improving the quality of test information services, while using Internet technology in the laboratory for RFID technology, wireless sensor network and ZigBee technology. Build a common speech and open platform. Based on the comprehensive collection and indepth analysis of test data, the platform provides applications and services for collaboration, sharing and application to fully meet the needs of different users (such as educators, students, and trial administrators), and focus on monitoring And manage university laboratories. In order for the country to better cultivate its engineering talents in the new era, this is important and historically significant.
\end{abstract}

Keywords: Internet of Things; Smart Laboratory System; Construction Framework

\section{Introduction}

The Internet of Things originated from the media industry and is the third innovation in the information industry. The Internet of Things refers to the use of sensing devices to connect anything in the network with information in accordance with agreed conditions. Objects exchange and communicate through information and media to identify professional knowledge, positioning, tracking, monitoring and other functions. The positioning of Internet products facing globalization is mainly concentrated in three areas:

Copyright (C) 2020 Xin ying,Wang

doi: $10.18282 / 1-$ e.v9i4.1682

This is an open-access article distributed under the terms of the Creative Commons Attribution Non-Commercial License (http://creativecommons.org/licenses/by-nc/4.0/), which permits unrestricted non-commercial use, distribution, and reproduction in any medium, provided the original work is properly cited.

\section{References}

[1]Biqing H, Feng P, Zhongyuan H . Planning Overall Landscapes,Building a Garden City:on the Revision of Guangzhou Urban Green Space System Planning[J]. Journal of Landscape Research, 2013(Z3).

[2]Zhang Xinwen, Shandong Agricultural University, Taian (China). RESEARCH ON ECOLOGICAL PLANNING METHOD

OF NORTH CHINA COASTAL WETLAND__ Taking Jincang National Wetland Park Master Plan in Laizhou Bay of Shandong Province as an Example[J]. Journal of Shandong Agricultural University, 2013.

[3]Zhen-Xing L I, Bi-Jun H, Shi-Lei F U , et al. Landscape Ecological Planning and Design of Urban Wetland Leisure Hotel[J]. heilongjiang agricultural sciences, 2016.

[4]Alves, Michelle, Ferreira, Joaquim Pedro, Torres, Inês. Habitat Use and Selection of the Marsh Harrier Circus aeruginosus in an Agricultural-Wetland Mosaic[J]. Ardeola Revista Iberica De Ornitologia, 2014, 61(2):351-366.

[5]Santelmann, Mary. Modeling Effects of Alternative Landscape Design and Management on Water Quality and Biodiversity in Midwest Agricultural Watersheds[J]. 2015.

[6]Barau A S , Qureshi S . Using agent-based modelling and landscape metrics to assess landscape fragmentation in Iskandar Malaysia[J]. Ecological Processes, 2015, 4(1):8. 


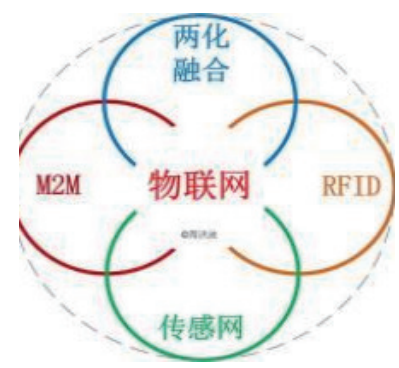

The first practical direction is called "smart dust", and it suggests combining different sensor devices to create a smart functional network ${ }^{[1]}$.

The network of known objects based on RFID technology is the second indicator. It is to support asset management and the advantages of object recognition and object recognition information, while at the same time building logical mining knowledge by combining information.

The third most effective indicator is the Internet of Things, which has the importance of data integration. It believes that the Internet has created a vast ocean of data. The accurate identification of each data identifier should be used to fully understand the use of the tool. This is not only a requirement for the intensive development of the Internet, but also a requirement for the Internet of Things.

\section{Management status of laboratories among universities}

With the rapid development of the national economy and various enterprises, the construction of laboratories in universities in various regions is also very important. Although our country has made considerable progress in this regard, the level of popularization still needs to be improved. In addition, some universities are still conducting manual management. Moreover, most of the equipment in many university laboratories in our country is outdated, the maintenance and control of technology are very backward, and the storage, query and distribution of test data are inefficient, which has seriously affected the implementation of education in our country. Moreover, some laboratories have high requirements for temperature, humidity and vibration effects, so management in this area is very difficult ${ }^{[2]}$.

\section{Significance and goals of building a smart laboratory under the Internet of Things environment}

The scope and scale of storage and refurbishment of laboratory equipment in colleges and universities has increased year by year, and management has become more and more difficult, especially in some professional laboratories with higher requirements, which sometimes require long-term dynamic monitoring. Compared with the mainstream Internet, because the Internet of Things searches for a large number of sensors that occupy different information sources, it can use the identification Internet, wireless communication and Internet technology to remotely control the real-time information. This greatly improves the quality and level of laboratory work. The construction of the university laboratory of the Internet of Things has changed the chaos and background management system of university laboratory information records ${ }^{[3]}$.

The construction of university laboratories in the context of the Internet of Things must meet the basic needs of university teaching and be forward-looking. Focus on the development and training of the Internet of Things technology, pay attention to the general degree of students' use of the Internet of Things in the laboratory, establish a comprehensive laboratory that meets the characteristics of the university's technology, promote and encourage innovation; improve scientific research methods so that the basics can be successfully completed here Student testing, curriculum design, production process, graduation project and related activities.

\section{The construction framework of smart laboratory system under the Internet of things environment}

\subsection{The overall overall plan of the smart laboratory}

The wisdom laboratory is composed of 5 functional systems. The five functional systems are: (1) Intelligent indoor management system under wireless sensors: (2) Experiment box management system: (3) Equipment management system based on RFID technology: (4) Intelligent energy management under power line communication System:

(1) Intelligent indoor management system. Through the console and mobile smart terminal, household appliances such as lighting, curtains and air conditioners can be controlled, and temperature, humidity and smoke can be monitored, stored and controlled in real time. Using wireless sensors, the temperature, humidity and light parameters in a specific area can be detected, and the controllable end is effective. For example, when it is found that the internal temperature has reached a certain set value, the air conditioner can be automatically turned on. Changes in smoke can be monitored in real time; and potential dangers can be warned.

(2) Experiment box management system. The connection between each test box and the server is achieved through a wireless network. During the test, the teacher can view the evaluation progress of each learner on the server side of the server to better understand the student's learning progress, and help teachers find and solve problems over time. The test box can provide electronic sign-in for students who are testing to achieve the goal of paperless management in the laboratory ${ }^{[5]}$.

(3) RFID equipment management system. The system mainly completes the management function of the equipment in the laboratory. The detailed description is as follows:

Tool kits of equipment and supplies: the purchase and storage of laboratory equipment play an important role in equipment 
issues and correct locations;

Instrument borrowing management: through the management platform, teachers can borrow equipment to use;

Equipment maintenance records: record equipment maintenance and drawings; record issues: record and use equipment information issues;

Location monitoring: In addition to the actual settings, install stop tags with sensor functions on important equipment. When the equipment moves from a specific location, an alarm will also be issued.

Intelligent energy management system. Through telecommunications and remote control, the load can be effectively distributed, efficiency can be achieved, and real-time collection and monitoring of power and communication status can be effectively saved. It can also alarm the values related to parameters exceeding the preset settings ${ }^{[6]}$.

\subsection{Use of technical methods}

The smart laboratory system is constructed using wireless and wired frameworks and can be quickly deployed and installed. These five operating systems are described in the visual interface of the Internet for Common Experience. It is mainly composed of three central parts: the wireless network base is sent to the laboratory, the multi-layer wireless Mesh network is installed, and the overall area for monitoring and control. Based on wireless sensor technology, RFID technology, power line communication and video surveillance system, etc. these technical content.

\section{Conclusion}

With the mature development of IoT technology, it has opened up a broad application space for the construction of laboratories in universities. At the same time, it also provides a free and flexible experimental base for learners, which is of great significance for enhancing students' independent innovation ability. In addition, the energy consumption of the laboratory is reduced to the maximum, which improves the safety of the laboratory. To establish a smart laboratory system, we must combine the teaching and scientific research needs of the university, and conduct sufficient analysis and research on the purpose and content of the construction, so as to provide scientific foundation and technical support for the construction of the Internet of Things laboratory.

\section{References}

[1]Sun Huailai. Application analysis of communication engineering technology in the field of Internet of Things[J]. Science and Technology Innovation and Application, 2020, No.317,168-169.

[2]Lin Hao. The application of Internet of Things and mobile Internet technology in the maintenance of urban rail transit equipment[J]. China Equipment Engineering, 2020, No.452, 83-84. 